\title{
Opposing roles of STAT1 and STAT3 in T cell-mediated hepatitis: regulation by SOCS
}

\author{
Feng Hong, Barbara Jaruga, Won Ho Kim, Svetlana Radaeva, Osama N. El-Assal, \\ Zhigang Tian, Van-Anh Nguyen, and Bin Gao
}

Section on Liver Biology, Laboratory of Physiologic Studies, National Institute on Alcohol Abuse and Alcoholism, National Institutes of Health, Bethesda, Maryland, USA

T cell-mediated fulminant hepatitis is a life-threatening event for which the underlying mechanism is not fully understood. Injection of concanavalin A (Con A) into mice recapitulates the histological and pathological sequelae of $\mathrm{T}$ cell-mediated hepatitis. In this model, both signal transducer and activator of transcription factor 1 (STAT1) and STAT3 are activated in the liver. Disruption of the STAT1 gene by way of genetic knockout attenuates liver injury, suppresses $\mathrm{CD}^{+}$and $\mathrm{NK} T$ cell activation, and downregulates expression of proapoptotic interferon regulatory factor- 1 protein and suppressor of cytokine signaling-1 (SOCS1), but enhances STAT3 activation and STAT3-controlled antiapoptotic signals. Studies from IFN- $\gamma$-deficient mice indicate that IFN- $\gamma$ not only is the major cytokine responsible for STAT1 activation but also partially accounts for STAT3 activation. Moreover, downregulation of STAT3 activation in IL-6-deficient mice is associated with decreased STAT3controlled antiapoptotic signals and expression of SOCS3, but upregulation of STAT1 activation and STAT1-induced proapoptotic signals and exacerbation of liver injury. Taken together, these findings suggest that STAT1 plays a harmful role in Con A-mediated hepatitis by activation of $\mathrm{CD}^{+}$and NK T cells and directly inducing hepatocyte death, whereas STAT3 protects against liver injury by suppression of IFN- $\gamma$ signaling and induction of antiapoptotic protein Bcl- $X_{\mathrm{L}}$. STAT1 and STAT3 in hepatocytes also negatively regulate one another through the induction of SOCS.

J. Clin. Invest. 110:1503-1513 (2002). doi:10.1172/JCI200215841.

\section{Introduction}

$\mathrm{T}$ cell-mediated immune responses play a central role in hepatocellular injury induced by autoimmune hepatitis, viral infection, alcohol consumption, and hepatotoxins (1-5). Activated $\mathrm{T}$ cells are detected in a variety of human liver diseases. For example, $\mathrm{CD} 4^{+} \mathrm{T}$ cells are the predominant population of $\mathrm{T}$ cells infiltrating into the liver in human autoimmune liver disease (6). In chronic active hepatitis $\mathrm{B}$ or $\mathrm{C}$, both $\mathrm{CD}^{+} \mathrm{T}$ cells and $\mathrm{CD} 8^{+} \mathrm{T}$ cells have been implicated in progression of liver injury and viral clearance (7-10). Additionally, infiltrating $\mathrm{CD}^{+}$and $\mathrm{CD} 8^{+}$lymphocytes in the liver significantly correlate with regenerating nodules, intralobular inflammation, and central sclerosis in alcoholic liver disease (5). T cell-mediated hepatitis can be induced in rodents by injection of the $\mathrm{T}$ cell

Received for publication May 2, 2002, and accepted in revised form September 24, 2002.

Address correspondence to: Bin Gao, Section on Liver Biology, NIAAA, NIH, Park Building, Room 120, 12420 Parklawn Drive, MSC 8115, Bethesda, Maryland 20892, USA. Phone:

(301) 443-3998; Fax: (301) 480-0257; E-mail: bgao@mail.nih.gov. Conflict of interest: The authors have declared that no conflict of interest exists.

Nonstandard abbreviations used: concanavalin A (Con A); Janus kinase-signal transducer and activator of transcription factor (JAK-STAT); suppressor of cytokine signaling (SOCS); cytokineinducible SH2-containing protein (CIS); carbon tetrachloride (CCl4); interferon regulatory factor-1 (IRF-1); enhanced chemifluorescence reaction (ECF); hematoxylin-eosin (H\&E); alanine transaminase (ALT); mononuclear cells (MNCs). mitogenic plant lectin concanavalin A (Con A), which rapidly induces clinical and histological evidence of hepatitis, including elevation of transaminase activities, within 8-24 hours (11). Liver histology shows massive granulocyte accumulation, $\mathrm{T}$ cell infiltration, necrosis, and apoptosis. The molecular and cellular mechanisms underlying Con A-induced hepatitis have been extensively investigated, but it is still not fully understood. Multiple cells and cytokines have been implicated in Con A-induced hepatitis (11-15), suggesting that $\mathrm{T}$ cell-mediated hepatitis results from the interactions of multiple cells and cytokines. However, the nature of such interactions and their roles in $\mathrm{T}$ cell-mediated hepatitis remain poorly understood.

The Janus kinase-signal transducer and activator of transcription factor (JAK-STAT) signaling pathway, activated by more than 40 cytokines and growth factors, has been implicated in a variety of cellular functions (16-19). In general, binding of these cytokines to their receptors induces receptor dimerization, tyrosine phosphorylation of the receptor-associated JAKs, followed by activation of the STATs, including STAT1, 2, $3,4,5$, and 6. Phosphorylated STATs form dimers and translocate to the nucleus to activate the transcription of many target genes, including a family of inhibitory proteins, suppressor of cytokine signaling (SOCS) (20-22), which then turn off the JAK-STAT signaling pathway. The SOCS family consists of eight proteins: SOCS1-SOCS7 and cytokine-inducible SH2-containing protein (CIS). SOCS1-SOCS3 and CIS are rapidly 
induced in response to stimulation by a wide variety of cytokines and negatively regulate cytokine signaling by inhibiting the JAKs. There is little evidence that SOCS4-SOCS7 are induced by cytokines and inhibit cytokine signaling. In the liver, the JAK-STAT signaling pathway plays an important role in liver development (23), acute-phase response (24), regeneration (25), protection against liver injury induced by carbon tetrachloride (CCl4) (26), Fas (27), and alcohol (28), as well as antiviral defense in the liver (29-31).

In this study, we demonstrate that injection of Con A rapidly induces activation of multiple JAK-STATs and their inhibitory proteins, SOCSs (20-22). Our findings suggest that Con A-mediated hepatitis is tightly regulated by STAT1 and STAT3, which modulate $\mathrm{CD}^{+}{ }^{+}$and NKT cell activation, and expression of apoptosis-associated genes. Activated STAT1 and STAT3 in hepatocytes also negatively regulate one another through the induction of SOCS.

\section{Methods}

Materials. Anti-STAT1, anti-phospho-STAT1 $\left(\mathrm{Tyr}^{701}\right)$, anti-phospho-STAT3 (Tyr ${ }^{705}$ ), anti-STAT3, anti-phospho-STAT5 (Tyr ${ }^{694}$ ), anti-phospho-STAT6 (Tyr ${ }^{641}$ ), and anti-phospho-Tyk2 $\left(\mathrm{Tyr}^{1054 / 1055}\right)$ were obtained from Cell Signaling (Beverly, Massachusetts, USA). Anti-phospho-STAT4 (Tyr $\left.{ }^{693}\right)$ was obtained from Zymed Laboratories Inc. (South San Francisco, California, USA). Anti-STAT2, anti-p21 cip1/waf1, anti-p53, anti-caspase-3, anti-phospho-JAK2 (Thr $\left.{ }^{1007} / \mathrm{Tyr}^{1008}\right)$, and anti-phospho-tyrosine Ab's were purchased from Upstate Biotechnology Inc. (Lake Placid, New York, USA). Anti-Bcl-2 and anti-Bcl- $X_{L}$ Ab's were obtained from BD PharMingen (San Diego, California, USA). Anti-CIS and anti-interferon regulatory factor-1 (anti-IRF-1) were purchased from Santa Cruz Biotechnology Inc. (Santa Cruz, California, USA). Anti-phospho-JAK1 ( $\left.\mathrm{Thr}^{1022} / \mathrm{Tyr}^{1023}\right)$, murine IFN- $\gamma$ and IL-6 were purchased from BioSource International (Camarillo, California, USA).

Genetically manipulated mice. Male C57BL/6J background $I L-6^{-/-}$mice and control mice, male BALB/cJ background $I F N-\gamma^{-/}$and control mice weighing 20-25g were purchased from The Jackson Laboratory (Bar Harbor, Maine, USA). Male 129/SvEv background $\mathrm{STAT1}^{-/-}$mice and control mice were purchased from Taconic Farms (Germantown, New York, USA). Preliminary data showed that C57BL/6J mice exhibit more susceptibility to Con A-induced liver injury than BALB/cJ and 129/SVEv mice. Thus, in this article, $10 \mu \mathrm{g} / \mathrm{g}$ of Con $\mathrm{A}$ was injected into C57BL/6J background wild-type and knockout mice, $15 \mu \mathrm{g} / \mathrm{g}$ of Con A was injected into BALB/cJ background wild-type and knockout mice, and $22 \mu \mathrm{g} / \mathrm{g}$ of Con A was injected into 129/SVEv background wildtype and knockout mice.

Primary mouse hepatocyte isolation and culture. Primary mouse hepatocyte isolation and culture were performed as described previously (31).
Tissue extraction, SDS-PAGE, and Western blot analysis. Tissue extraction, SDS-PAGE, and Western blot analysis were performed as described previously (31). All wildtype and knockout mouse samples for each individual protein or RNA (14 samples, see Figures 2d, 4a, and 5a; 12 samples, see Figure 3 , a and b) were done in the same blot to accurately quantify and compare them. Protein bands were visualized by an enhanced chemifluorescence reaction (ECF) (Amersham Pharmacia Biotech, Piscataway, New Jersey, USA) and scanned with a Storm PhosphoImager (Molecular Dynamics, Sunnyvale, California, USA). The densities of bands were analyzed with ImageQuant software (Molecular Dynamics). The PSTAT1, pSTAT3, IRF-1, and Bcl- $X_{\mathrm{L}}$ protein levels were quantified using ImageQuant software and normalized to $\beta$-actin protein levels at each time point. Fold induction is the relative induction compared with untreated wild-type control mice.

RT-PCR. RT-PCR was performed as described previously (31), except $20-25$ cycles were used in this study. The sequences of the primers used in the study for murine SOCSs are as follows: SOCS1 (210 bp), 5' GAG GTC TCC AGC CAG AAG TG 3' (forward), 5' CTT AAC CCG GTA CTC CGT GA 3' (reverse); SOCS2 (300 bp), 5' AAG ACA TCA GCC GGG CCG ACT A 3' (forward), 5' GTC TTG TTG GTA AAG GTA GTC 3' (reverse); SOCS3 (450 bp), 5' GGA CCA GCG CCA CTT CTT CAC 3' (forward), 5' TAC TGG TCC AGG AAC TCC CGA 3 ' (reverse). The $\beta$-actin gene was also amplified as an internal control. $\beta$-actin primers were $5^{\prime}$ AAG GTG ACA GCA TTG CTT CT 3' (forward) and $5^{\prime}$ GGC TGC CTC AAC ACC TCA 3' (reverse). RNA without reverse transcription did not yield any amplicons; therefore, no genomic DNA contamination occurred. The PCR bands were scanned with a Storm PhosphoImager, and inverted ethidium bromide-stained bands are shown. The densities of bands were analyzed with ImageQuant software. SOCS1 and SOCS3 mRNA levels were quantified using ImageQuant software and normalized to $\beta$-actin mRNA levels at each time point. Fold induction is the relative induction compared with untreated wild-type control mice.

Hematoxylin-eosin staining of liver sections. Following fixation of the livers with $4 \%$ formalin/PBS, livers were sliced and stained with hematoxylin-eosin (H\&E) for histological examination.

Analysis of alanine transaminase activity. Liver injury was quantified by measurement of plasma enzyme activities of alanine transaminase (ALT) using a kit from Sigma-Aldrich (St. Louis, Missouri, USA).

ELISA. Plasma levels of cytokines were measured by using standard ELISA sandwich kits as specified by the manufacturer (BioSource International).

Isolation of liver mononuclear cells. Wild-type and knockout mouse livers were removed and pressed through a 200-gauge stainless steel mesh. The liver cell suspension was collected and suspended in RPMI-1640 medium (Life Technologies Inc., Gaithersburg, Maryland, USA). Parenchymal cells (pellet) were separated from mononuclear cells (MNCs) (supernatant) by centrifugation 


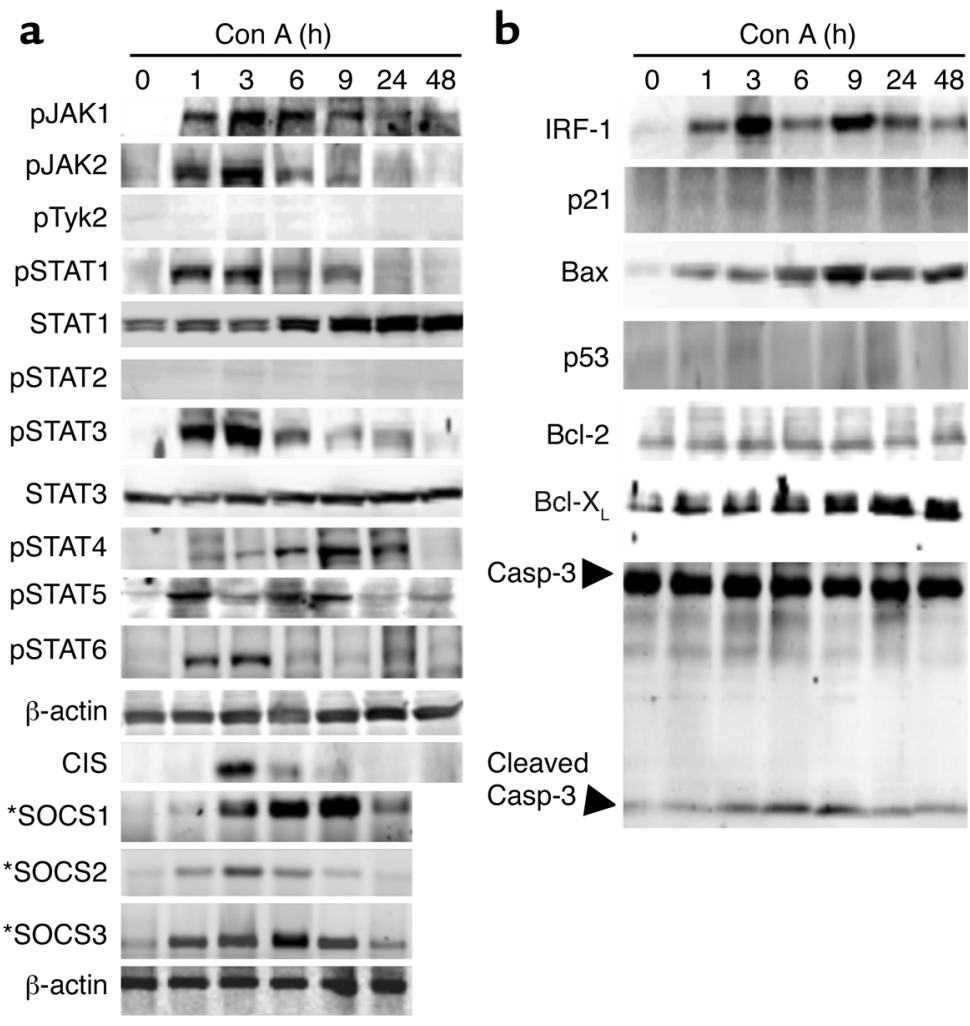

\section{Figure 1}

Activation of multiple JAKs, STATs, SOCS, and apoptosis-associated proteins in the liver after injection of Con A. (a) and (b) C57BL/6J mice were injected with Con A $(10 \mu \mathrm{g} / \mathrm{g})$ at various time points. Total liver protein extracts and RNA were prepared and analyzed by Western blotting and RT-PCR (indicated by asterisks), respectively, using Ab's and primers as indicated. Data are representative of three independent experiments with similar results. $p$, phosphorylated form.

shown in Figure 1a, STAT1, STAT3, STAT5, and STAT6 were activated in the liver with the peak effect occurring at 1-3 hours, whereas peak STAT4 activation was detected at 9 hours. Activation of STAT2 was not detected at any time point tested. Furthermore, injection of Con A significantly induced expression of both SOCS1 mRNA and SOCS3 mRNA, whereas it only slightly induced SOCS2 and CIS expression (Figure 1a).

The robust activation of STAT1 and STAT3 suggested that the downstream effectors of STAT1 and STAT3 may be important mediators of $\mathrm{T}$ cell-mediated hepatitis. STAT1 and STAT3 play compli-

at $50 \mathrm{~g}$ for 5 minutes. Supernatant containing MNCs was collected, washed in PBS, and resuspended in 40\% Percoll (Sigma-Aldrich) in RPMI-1640 medium. The cell suspension was gently overlaid onto $70 \%$ Percoll and centrifuged for 20 minutes at $750 \mathrm{~g}$. MNCs were collected from the interface, washed twice in PBS, and resuspended in RPMI-1640 medium.

Flow cytometry analysis of $\mathrm{CD}^{+} \mathrm{T}$ cell and $\mathrm{NK} T$ cell activation in the liver after administration of Con $A$. Activation of $\mathrm{CD} 4^{+} \mathrm{T}$ cells was determined by anti-CD4 plus antiCD69 (early activation marker) (BD PharMingen) using a FACScalibur (Becton Dickinson Immunocytometry Systems, Mountain View, California, USA). NK $T$ cell number was determined by anti-NK1.1 plus antiCD3 Ab's (BD PharMingen).

Statistics analysis. For comparing values obtained in three or more groups, one-factor ANOVA was used, followed by Tukey's post hoc test, and $P$ values less than 0.05 were taken to imply statistical significance.

\section{Results}

Activation of multiple JAKs, STATs, SOCSs, and proapoptotic and antiapoptotic proteins in Con A-induced hepatitis. After injection of Con A, plasma levels of a wide variety of cytokines are dramatically elevated (13). To determine the interaction of these cytokines in Con A-induced hepatitis, activation of the JAK-STAT signaling pathway in the liver was examined. As shown in Figure 1a, Con A injection rapidly induced activation of JAK1 and JAK2, but not Tyk2. Consistent with activation of JAK1 and JAK2, multiple STATs were also activated. As mentary, counterregulatory roles in apoptosis during Con A-induced hepatitis, because STAT1 activates the proapoptotic proteins IRF- 1 and p $21^{\text {cip } 1 / \text { waf } 1}(30,32)$, while STAT3 activates the antiapoptotic proteins Bcl-2 and Bcl- $X_{\mathrm{L}}(33)$. As shown in Figure 1b, IRF-1 was activated in a biphasic response, with significant peak induction at 3 hours and again at 9 hours. Expression of $\mathrm{Bcl}-\mathrm{X}_{\mathrm{L}}$ proteins was elevated with peak effect between 9 hours and 48 hours. Additionally, Bax, a proapoptotic protein, was significantly induced with peak effect at 9 hours. Caspase- 3 , an indicator of apoptosis, is generated as a $32-\mathrm{kDa}$ precursor, which is enzymatically cleaved into p17/p12 mature subunits (34). Caspase-3 was activated 3-9 hours after Con A injection, as assessed by generation of the mature $\mathrm{p} 17$ subunit. On the contrary, expression of $\mathrm{p} 21^{\text {cip } 1 / \text { waf1 } 1}, \mathrm{p} 53$, and Bcl-2 proteins was not altered after injection of Con $\mathrm{A}$.

Liver injury and STAT1 and SOCS1 activation are attenuated, but STAT3 and SOCS3 activation are enhanced and prolonged in Con A-induced hepatitis in STAT1 $1^{-1-}$ mice. To examine the potential role of STAT1 activation in T cell-mediated hepatitis, we compared Con Ainduced hepatitis in $S T A T 1^{-/-}$and $S T A T 1^{+/+}$mice. As shown in Figure 2, a and b, after injection of Con A, ALT activities were dramatically elevated in wild-type mice, but were not increased in $S T A T 1^{-/-}$mice. Examination of liver pathology showed massive necrosis in $S T A T 1^{+/+}$mice, but not in STAT1 $1^{-/-}$mice. A representative example of liver histology from $S T A T 1^{+/+}$and STAT1 $1^{-/}$mice obtained 9 hours after Con A injection is shown in Figure $2 b$. 
a

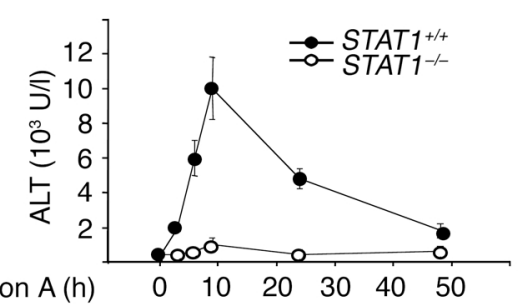

c

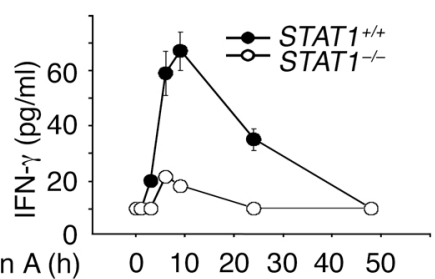

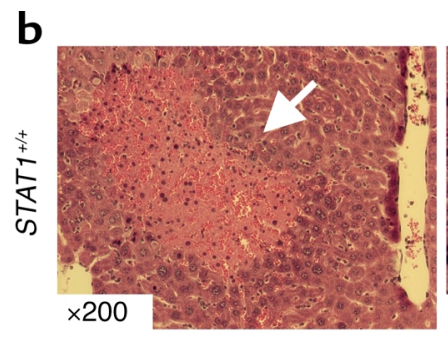
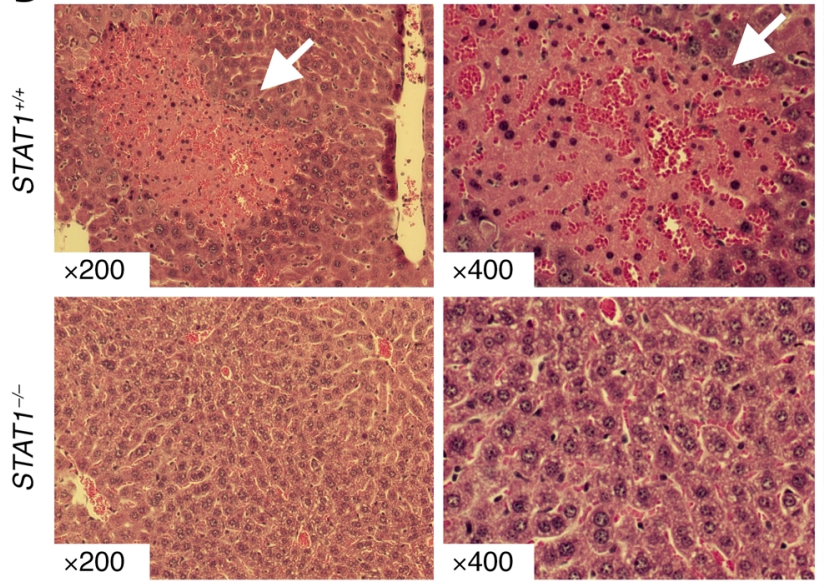

d

Con A (h) $\begin{array}{llllllllllllll} & 0 & 1 & 3 & 6 & 9 & 2448 & 0 & 1 & 3 & 6 & 9 & 24 & 48\end{array}$

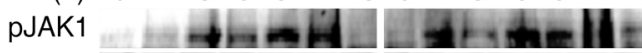

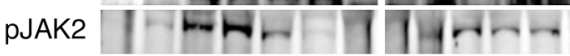
pSTAT1 $=-=\approx$

STAT1 $=== \pm$

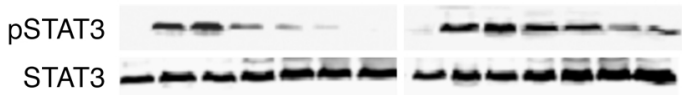

IRF-1
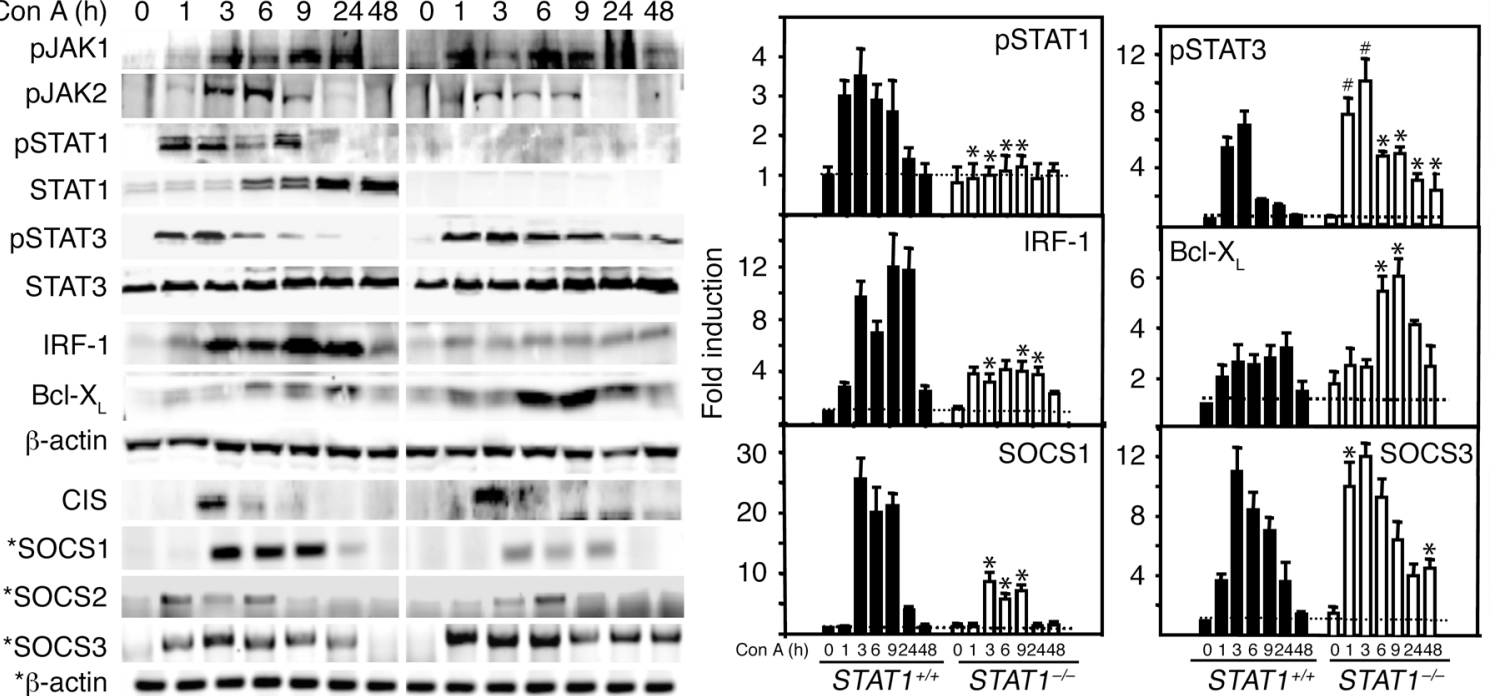

Figure 2

Liver injury and STAT1 and SOCS1 activation are attenuated, but STAT3 and SOCS3 activation are enhanced and prolonged in Con A-induced hepatitis in STAT1-/- mice. (a) Mice were injected with $22 \mu \mathrm{g} / \mathrm{g}$ of Con A. At various time points, serum ALT levels were measured. Values are shown as means \pm SEM from four mice at each time point. (b) Photomicrographs of representative mouse livers from 9-hour Con A-treated wild-type and STAT1-1- mice with $\mathrm{H} \& \mathrm{E}$ staining are shown (original magnification $\times 200$ and $\times 400$ ). White arrows indicate massive necrosis observed in the liver. (c) Wild-type control and STAT1-1- mice were injected with Con A (22 $\mu$ g/g). At various time points after injection, serum was collected, and circulating IFN- $\gamma$ levels were measured by ELISA. Values are shown as means \pm SEM from three mice at each time point. (d) Total liver protein extracts and RNA from Con A-treated STAT1 ${ }^{+/}$and STAT1-/- mice were analyzed by Western blotting and RT-PCR (indicated by asterisks), respectively, using Ab's and primers as indicated. Induction of pSTAT1, pSTAT3, IRF-1, Bcl-X $X_{L}$ SOCS1, and SOCS3 was quantified by Phosphorlmager analysis (left panel), as described in Methods. The values are shown as means \pm SEM from four independent experiments at each time point. ${ }^{*} P<0.001,{ }^{*} P<0.01$ vs. corresponding Con A-treated wild-type control groups at the same time points.

Since IFN- $\gamma$ has been shown to play an important role in Con A-induced hepatitis $(14,35)$, we compared the serum IFN- $\gamma$ levels in both wild-type and $S T A T 1^{-/-}$mice after injection of Con A. As shown in Figure 2c, Con A injection-induced elevation of IFN- $\gamma$ was significantly attenuated in $\mathrm{STAT1}^{-/-}$mice compared with wild-type mice. Next, we compared activation of the JAK-STAT signaling pathway in the liver of Con A-induced hepatitis in $\mathrm{STAT1}^{+/+}$and $\mathrm{STAT1}^{-{ }^{--}}$mice. As shown in Figure 2d, JAK1 activation remained unchanged and JAK2 activation was decreased in $\mathrm{STAT1}^{-/-}$mice compared with $S T A T 1^{+/+}$mice. Activation and induction of STAT1, as expected, were absent in $S T A T 1^{-/-}$mice, whereas activation of STAT3 was significantly enhanced and prolonged in these mice. Consistent with absent STAT1 activation and strong STAT3 activation in $S_{T A T 1^{-/}}$mice, induction of IRF-1 protein was not detected, whereas induction of $\mathrm{Bcl}-\mathrm{X}_{\mathrm{L}}$ protein was significantly enhanced in these mice (Figure 2d). Expression of SOCS in the liver of Con A-induced hepatitis was also examined. A 20- to 25-fold induction of SOCS1 mRNA expression was observed between 3 
hours and 9 hours in $S T A T 1^{+/+}$mice, whereas five- to eightfold induction was detected in $S T A T 1^{-/-}$mice (Figure $2 \mathrm{~d}$ ). In contrast with decreased SOCS1 induction, Con A injection-induced SOCS3 mRNA expression was significantly enhanced at 1 hour and 48 hours in $S T A T 1^{-/-}$mice compared with $S T A T 1^{+/+}$mice. Similar weak activation of SOCS2 and CIS was detected in both $S T A T 1^{+/+}$and $S_{T A T 1^{-/}}$mice.

IFN- $\gamma$ and IL-6 induce prolonged STAT3 activation in the STAT1 ${ }^{-1-}$ mouse hepatocytes. The above data indicate that Con A injection-induced STAT3 activation in the liver is prolonged in $S T A T 1^{-1-}$ mice, which could be due to either increased levels of STAT3-activating cytokines or increased response of $S T A T 1^{-/-}$hepatocytes to STAT3 activation. Our observation that Con A injectioninduced activation of JAKs was not enhanced in STAT1 ${ }^{-/-}$mice (Figure 2d) suggested that Con Ainduced prolonged activation of STAT3 in STAT1 ${ }^{-/}$ mice is not due to increased levels of STAT3 activating cytokines such as IL-6. Indeed, Con A injectioninduced elevation of serum IL-6 levels was decreased in $S T A T 1^{-/-}$mice compared with wild-type mice (data not shown). To examine whether STAT1 $1^{-/-}$hepatocytes were more susceptible to STAT3 activation, mouse hepatocytes from $S T A T 1^{+/+}$and $S T A T 1^{-/-}$mice were stimulated with IFN- $\gamma$ and IL-6, which are the two major cytokines responsible for STAT1 and STAT3 activation, respectively, in the livers of mice with Con A-induced hepatitis (see Figures 4 and 5). As shown in Figure $3 \mathrm{a}$, IFN- $\gamma$ treatment induced STAT1 activation and IRF-1 expression in $S T A T 1^{+/+}$mouse hepatocytes, but not in STAT1 $1^{-/}$mouse hepatocytes. On the contrary, the same IFN- $\gamma$ treatment caused prolonged STAT3 activation and enhanced $\mathrm{Bcl}-\mathrm{X}_{\mathrm{L}}$ expression in $S T A T 1^{-/-}$mouse hepatocytes (Figure 3a). IFN- $\gamma-$ induced SOCS1 mRNA expression was completely abolished in $\mathrm{STAT1}^{-/-}$mouse hepatocytes, whereas induction of SOCS3 mRNA expression was enhanced and prolonged in these cells, compared with wild-type cells (Figure 3a).

The effects of IL- 6 on STAT activation and SOCS induction in $S T A T 1^{+/+}$and $S T A T 1^{-/-}$mouse hepatocytes are shown in Figure 3b. IL-6 treatment caused weak STAT1 activation and IRF-1 induction in $S T A T 1^{+/+}$, but not in $S T A T 1^{-/-}$mouse hepatocytes. On the contrary, the same IL-6 treatment slightly enhanced STAT3 activation and $\mathrm{Bcl}-\mathrm{X}_{\mathrm{L}}$ protein expression in $\mathrm{STAT1}^{-/-}$ mouse hepatocytes compared with $S T A T 1^{+/+}$mouse hepatocytes. IL-6 treatment induced enhanced and prolonged SOCS3 mRNA expression in STAT1 $1^{-/}$ mouse compared with $S T A T 1^{+/+}$mouse hepatocytes, but did not affect SOCS1 mRNA expression in either cell type. Taken together, these findings suggest that Con A-induced prolonged activation of STAT3 in $S T A T 1^{-1-}$ mice is caused by increased response of STAT1 $1^{--}$hepatocytes to STAT3 activation.

Liver injury and STAT1 and SOCS1 activation are attenuated, whereas activation of STAT3 is slightly enhanced in Con $A$-induced hepatitis in IFN- $\gamma^{-1}$ mice. IFN- $\gamma$, which is elevated in the serum after administration of Con A (Figure 2c), is an important activator of STAT1 signaling. To explore the role of IFN- $\gamma / \mathrm{STAT} 1$ signaling in $\mathrm{T}$ cell-mediated hepatitis, we injected IFN- $\gamma^{-/}$mice with Con $\mathrm{A}$ and assessed the subsequent molecular and pathological changes in the liver. Con A injectioninduced STAT1 activation and induction were almost completely abolished in the liver of IFN- $\gamma^{\prime /}$ mice, whereas activation of STAT3 was slightly but not significantly enhanced in $I F N-\gamma^{/-}$mice compared with $I F N-\gamma^{+/+}$ mice; JAK1 and JAK2 activation were decreased in $I F N-\gamma^{\prime-}$ mice (Figure 4a). Consistent with weak STAT1 activation, IRF-1 gene expression was not upregulated in
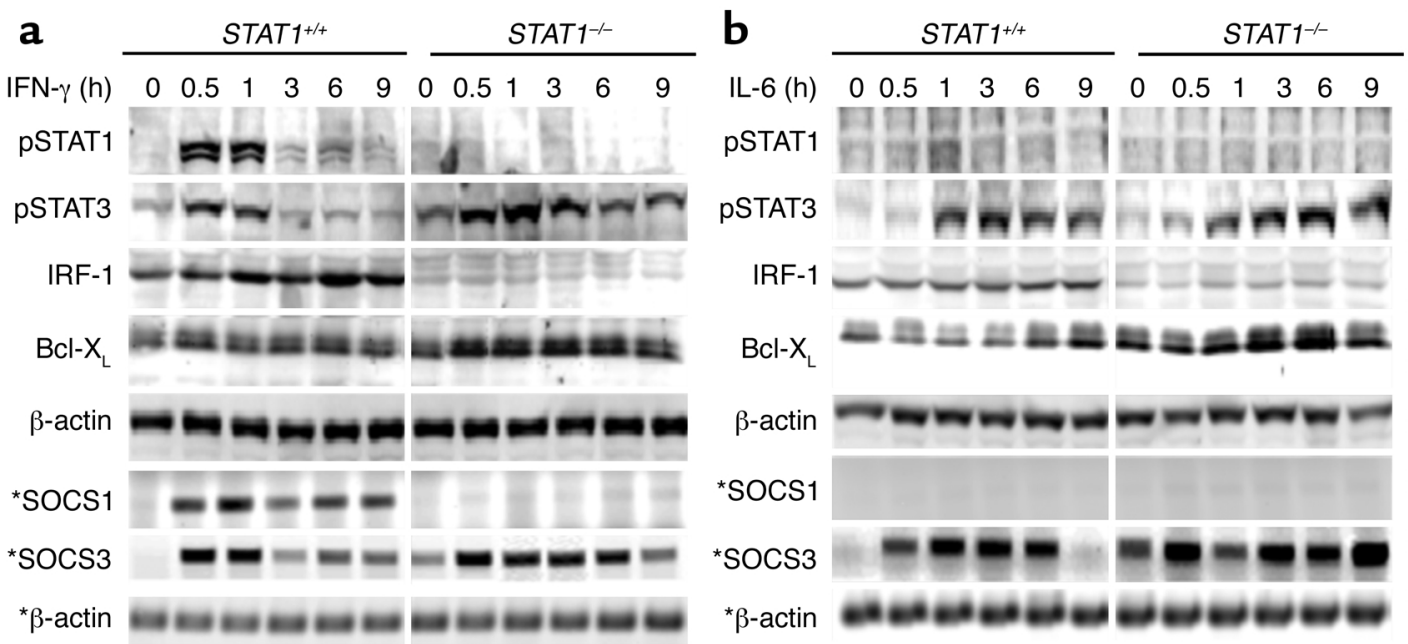

Figure 3

IFN- $\gamma$ and IL- 6 induce prolonged activation of STAT3 in STAT1 $1^{-/-}$mouse hepatocytes. Primary cultured mouse hepatocytes were treated with IFN- $\gamma(10 \mathrm{ng} / \mathrm{ml})$ or IL-6 $(20 \mathrm{ng} / \mathrm{ml})$. At various time points, as indicated, cell protein extracts and RNA were prepared and analyzed by Western blotting and RT-PCR (indicated by asterisks), respectively, using Ab's or primers as indicated. Similar data were obtained from five independent experiments. 
a

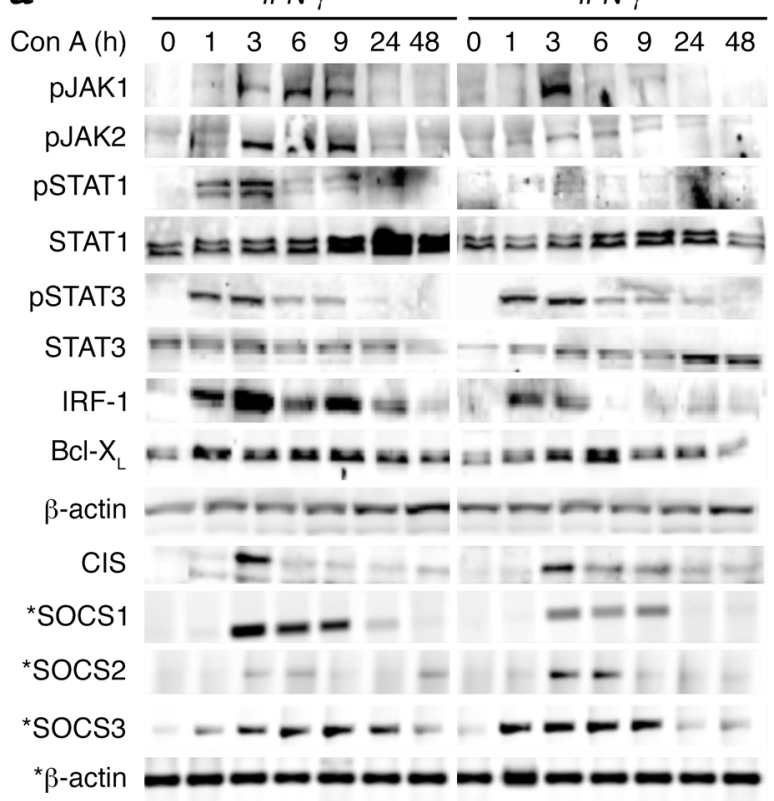

b

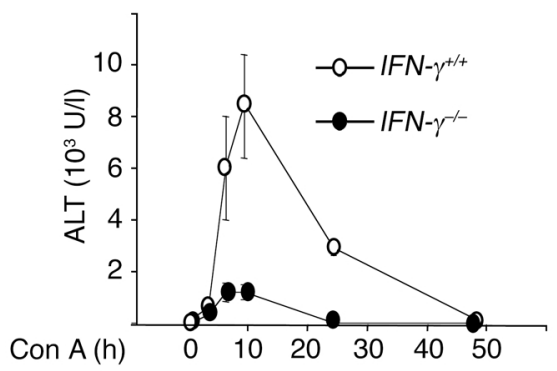

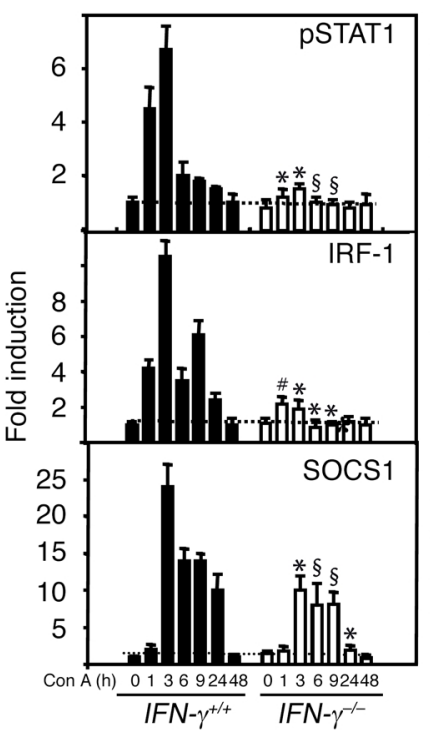
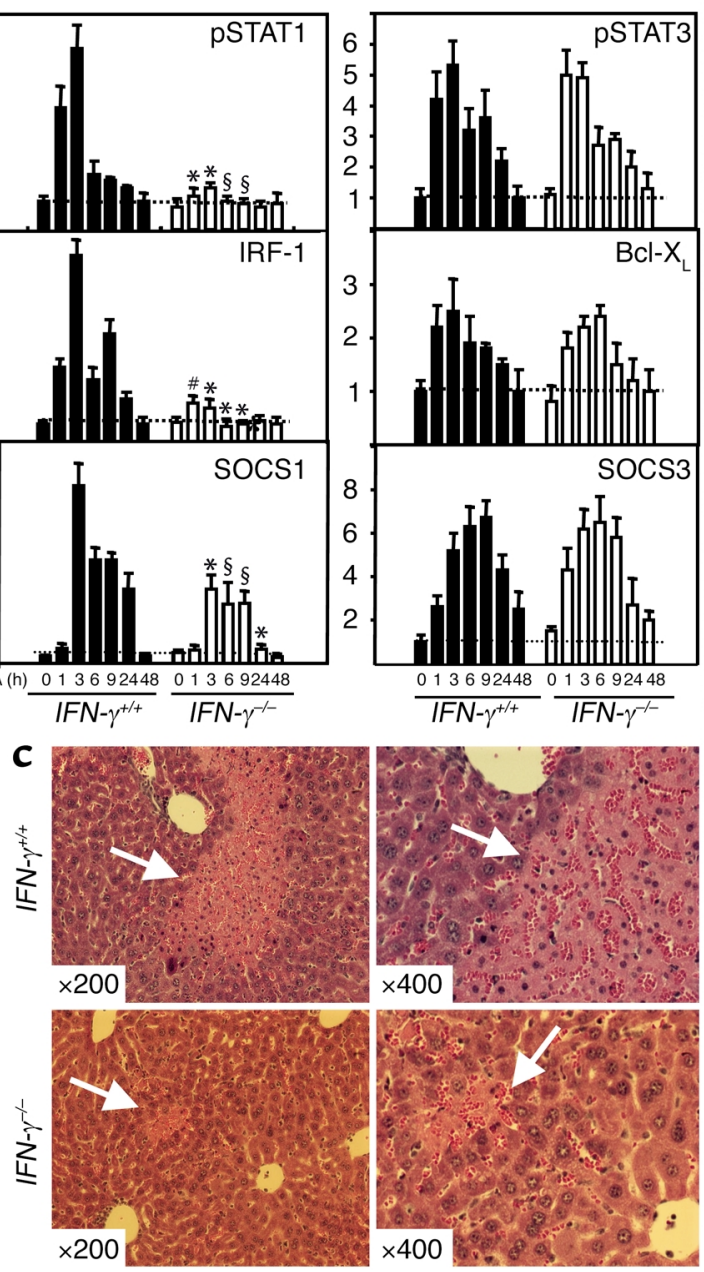

\section{Figure 4}

Liver injury, STAT1 and SOCS1 activation are attenuated, whereas STAT3 activation is slightly enhanced in Con A-induced hepatitis in IFN- $\gamma^{-/-}$mice. (a) IFN- $\gamma^{+/+}$mice and IFN- $\gamma^{-/}$mice were injected with $15 \mu \mathrm{g} / \mathrm{g}$ of Con A. At various time points, total liver protein extracts and RNA were prepared and analyzed by Western blotting and RT-PCR (indicated by asterisks), respectively, using Ab's and primers as indicated. Induction of PSTAT1, pSTAT3, IRF-1, Bcl-X L, SOCS1, and SOCS3 was quantified by Phosphorlmager analysis (left panel), as described in Methods. The values are shown as means \pm SEM from three independent experiments at each time point. ${ }^{*} P<0.001$, ${ }^{\#} P<0.01$, and $\S P<0.05$ vs. corresponding Con A-treated wild-type control groups at the same time point. (b) Serum ALT levels from these mice were measured. Values shown as means \pm SEM from three mice at each time point. (c) Photomicrographs of representative mouse livers from 9-hour Con A-treated mice with $\mathrm{H} \& \mathrm{E}$ staining are shown (original magnification $\times 200$ and $\times 400$ ). White arrows indicate massive necrosis observed in the liver.

$I F N-\gamma^{-/}$mice. $\mathrm{Bcl}-\mathrm{X}_{\mathrm{L}}$ protein expression was slightly reduced in $I F N-\gamma^{-/}$mice compared with $I F N-\gamma^{+/+}$mice. Additionally, a 13- to 24-fold induction of SOCS1 mRNA was observed between 3 hours and 9 hours after injection of Con A in IFN- $\gamma^{+/+}$mice, whereas only a eightto tenfold increase was detected in ${\mathrm{IFN}-\gamma^{-1}}^{-}$mice (Figure 4a). Furthermore, induction of SOCS3 expression was slightly but not significantly enhanced in $I F N-\gamma^{/-}$mice compared with $I F N-\gamma^{+/+}$mice. Weak activation of SOCS2 and CIS was seen in both $I F N-\gamma^{+/+}$and $I F N-\gamma^{/-}$mice.

Next we compared Con A-induced liver injury in $I F N-\gamma^{+/+}$and $I F N-\gamma^{-/}$mice. As shown in Figure 4b, injection of Con A significantly induced serum ALT levels in $I F N-\gamma^{+/+}$mice, with a peak effect at 9 hours; in comparison, serum ALT levels were not significantly increased in $I F N-\gamma^{/-}$mice. Examination of liver histology showed massive necrosis in $I F N-\gamma^{+/+}$mice, whereas
$I F N-\gamma^{/-}$mice appeared to be largely protected from hepatic injury. A representative example of liver histology from 9-hour Con A-injected $I F N-\gamma^{+/+}$mice and $I F N-\gamma^{/-}$mice is shown in Figure 4c.

STAT3 and SOCS3 activation are attenuated, but liver injury, STAT1 activation, and STAT1-controlled IRF-1 are enhanced, in Con A-induced hepatitis in IL-6 $6^{-/-}$mice. STAT3 and its downstream antiapoptotic factors such as $\mathrm{Bcl}-2$ and $\mathrm{Bcl}-\mathrm{X}_{\mathrm{L}}$ are largely activated by the cytokine IL-6. To determine the role of IL-6/STAT3 signaling in hepatitis, $I L-6^{-/-}$mice were injected with Con A, and the subsequent molecular and pathological changes in the liver were assessed. As shown in Figure 5a, Con A injection-mediated activation of STAT3 was markedly attenuated at 1 and 3 hours, whereas STAT1 activation was significantly potentiated at 3,6 , and 9 hours in $I L-6^{-/-}$mice compared with $I L-6^{+/+}$mice; JAK1 and JAK2 
activation were downregulated in $I L^{-6^{-/-}}$mice. Consistent with upregulation of STAT1 activation, induction of IRF-1 gene expression was enhanced in $I L-6^{-/}$mice. On the contrary, induction of $\mathrm{Bcl}-\mathrm{X}_{\mathrm{L}}$ protein was diminished in $I L-6^{-/}$mice, which correlated with downregulation of STAT3 activation in these mice. Con A injection-induced SOCS mRNA expression was also examined. As shown in Figure 5a, Con A injection-induced SOCS1 mRNA expression was enhanced and prolonged, whereas SOCS3 mRNA induction was attenuated in $I L-6^{-/-}$mice compared with $I L-6^{+/+}$mice. Furthermore, weak induction of CIS observed in $\mathrm{IL}^{-6^{+/+}}$ mice was barely detected in $I L^{-6^{-/}}$mice. Similar activation of SOCS2 was seen in both $I L-6^{+/+}$and $\mathrm{IL}^{-6^{-/}}$mice. Liver injury was also compared in $I L-6^{+/+}$and $I L-6^{-/-}$ mice. As shown in Figure 5b, Con A injection-induced elevation of ALT levels was markedly increased and prolonged in $I L-6^{-/-}$mice compared with $I L-6^{+/+}$control mice. Likewise, histological examination of liver revealed much more sever necrosis in $\mathrm{IL}^{-6^{-/-}}$mice a

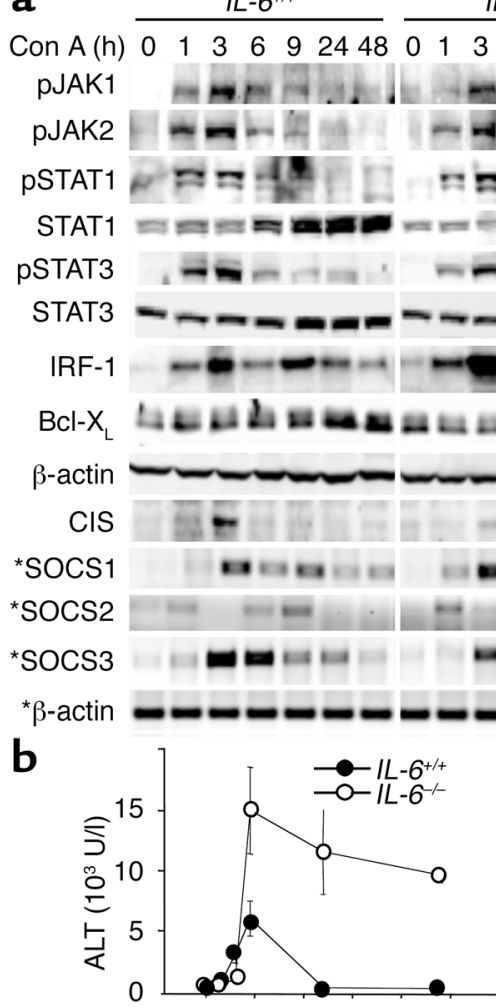

Con A (h) $0 \quad 10 \quad 20 \quad 30 \quad 40 \quad 50$
$1 L-6^{-/-}$

$\begin{array}{lll}6 & 9 & 2448\end{array}$

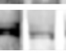

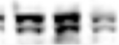
$-m-$ $-\infty$
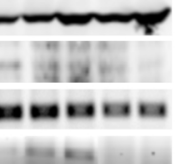

C

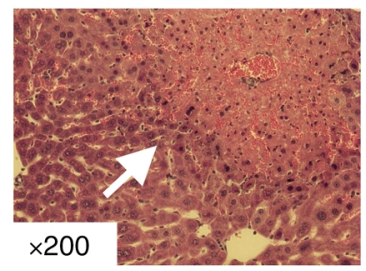

$1 L-6^{+/+}$Con A-treated

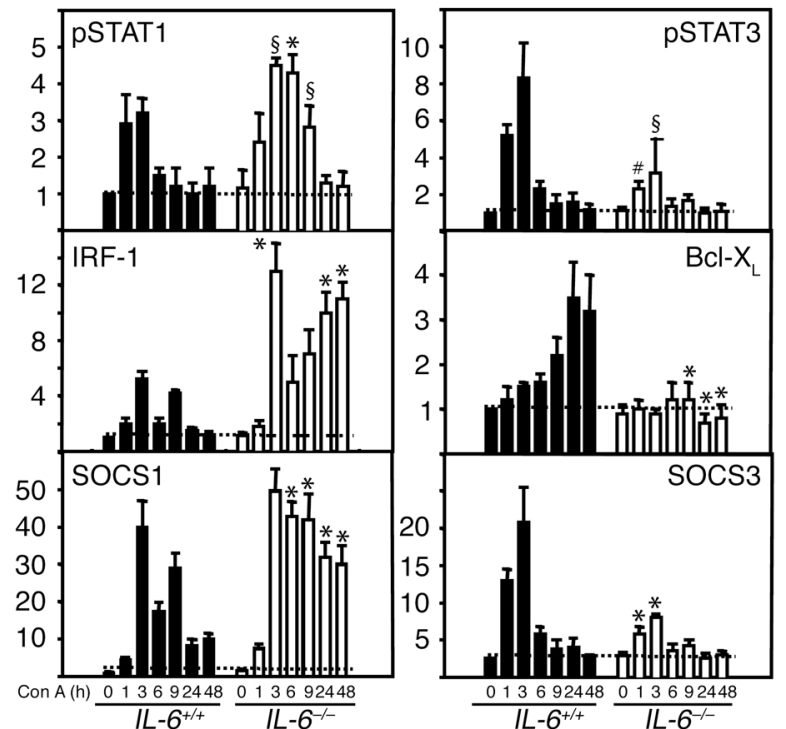

d

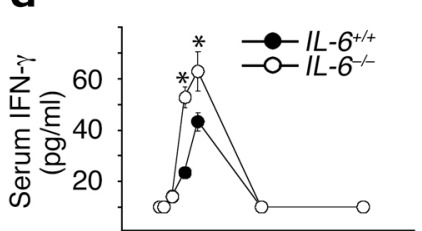

Con A (h) 01020304050

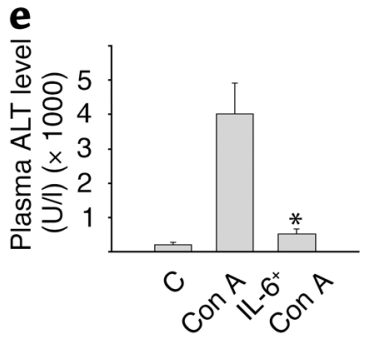

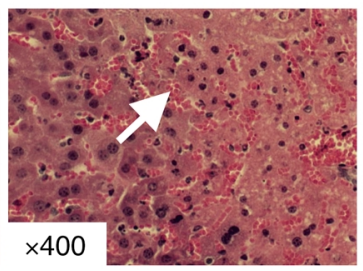

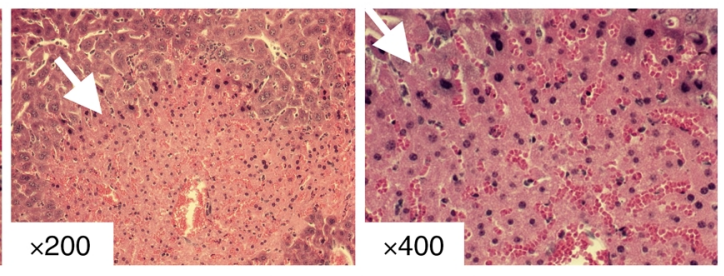

IL- $6^{-1-}$ Con A-treated

\section{Figure 5}

STAT3 and SOCS3 activation are attenuated, but liver injury, STAT1, IRF-1, and SOCS1 activation are enhanced in Con A-induced hepatitis in $I L-6^{-/-}$mice. (a) $I L-6^{+/+}$mice and $I L-6^{-/-}$mice were injected with $10 \mu \mathrm{g} / \mathrm{g}$ of Con A. At various time points, liver protein extracts and RNA were analyzed by Western blot or RT-PCR (indicated by asterisks), respectively, using Ab's and primers as indicated (left panel), and quantified by Phosphorlmager analysis (right panel). The values are shown as means \pm SEM from four independent experiments. ${ }^{*} P<0.001$, ${ }^{\#} P<0.01, \S P<0.05 \mathrm{vs}$. corresponding control groups at the same time point. (b) Serum ALT levels from these mice were measured. Values are shown as means \pm SEM from four mice at each time point. (c) Photomicrographs of representative mouse livers obtained 9 hours after Con $A$ injection with $\mathrm{H} \& \mathrm{E}$ staining are shown (original magnification $\times 200$ and $\times 400$ ). White arrows indicate massive necrosis observed in the liver. (d) Wild-type control and $I L-6^{-/-}$mice were injected with Con A $(10 \mu \mathrm{g} / \mathrm{g})$. At various time points, serum IFN- $\gamma$ levels were measured. Values are shown as means \pm SEM from three mice at each time point. ${ }^{*} P<0.001$ vs. corresponding Con A-treated wild-type control groups at the same time points. (e) C57BL/6J mice were injected (intravenously) with IL- $6(2 \mu \mathrm{g} / \mathrm{g})$, followed 6 hours later by injection of Con A $(10 \mu \mathrm{g} / \mathrm{g})$. After 8 hours, serum ALT levels were measured. Values shown are means \pm SEM from five mice. Significant difference from corresponding Con A-treated group is indicated by asterisks. ${ }^{*} P<0.01$. 

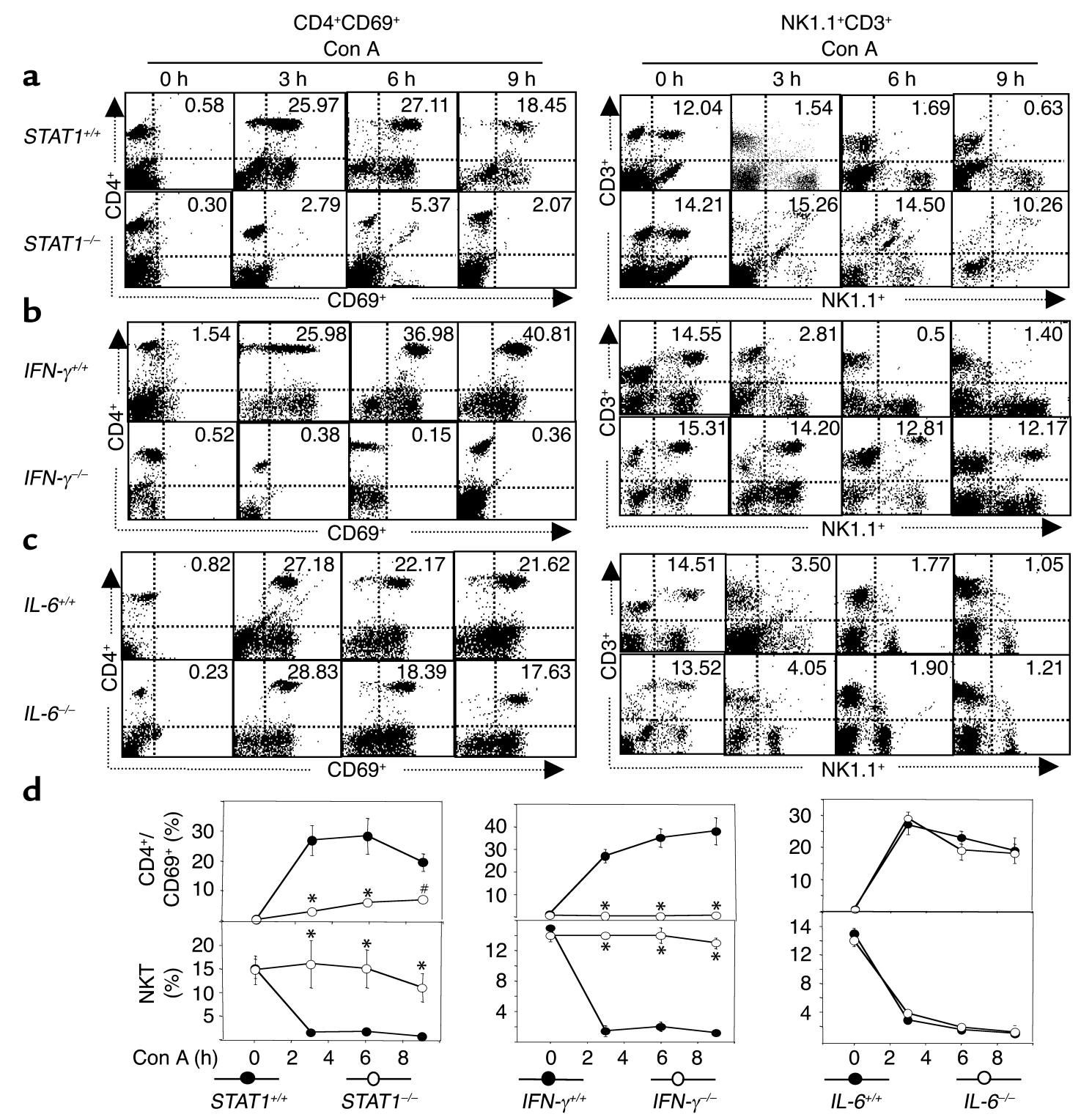

Figure 6

Con A injection-mediated activation of $\mathrm{CD}^{+}$and NKT cells is abolished in STAT1-/- and IFN- $\gamma^{-/-}$but not in $/ L_{-} 6^{-/-}$mice. Wild-type and knockout mice were injected with Con A for 3, 6, and 9 hours. Hepatic lymphocytes were isolated. The surface of CD $4^{+} \mathrm{CD} 69^{+}$or $\mathrm{NK} 1.1^{+} \mathrm{CD} 3^{+}$was analyzed by flow cytometry. The flow cytometric analysis is representative of three independent experiments. The upper-right quadrant in each panel shows $\mathrm{CD}^{+} \mathrm{CD} 69^{+}$or $\mathrm{NK} 1.1^{+} \mathrm{CD} 3^{+}$double-positive cells (percentage of the total hepatic lymphocytes). Values are shown in $\mathbf{d}$ as means \pm SEM from three mice at each time point. ${ }^{*} P<0.001$ and ${ }^{\#} P<0.01$ vs. corresponding Con A-treated wild-type groups at the same time points.

compared with $I L-6^{+/+}$control mice (Figure 5c). Finally, the levels of serum IFN- $\gamma$ in wild-type and $I L-6^{-/-}$mice were determined. As shown in Figure 5d, elevation of serum IFN- $\gamma$ levels at 3 and 9 hours after administration of Con A is significantly enhanced in $I L^{-6^{-/-}}$mice compared with wild-type mice.

The above data indicate that Con A-induced liver injury is exacerbated in $I L-6^{-/-}$mice, suggesting that IL-6 imparts protective effects against hepatic injury. To explore this hypothesis, we examined whether administration of IL- 6 protects against Con A-induced liver injury. As shown in Figure 5e, injection of IL-6 markedly suppressed Con A-induced liver injury, consistent with a previous report (36).
Con A injection-mediated activation of $\mathrm{CD}^{+}$and $\mathrm{NKT}$ Cells is abolished in STAT1 $1^{-/}$and IFN- $\gamma^{-/-}$mice but remains unchanged in $\mathrm{IL}_{-6^{-/-}}$mice. Activation of $\mathrm{CD}^{+}$and $\mathrm{NK} \mathrm{T}$ cells, which have been shown to play an important role in Con A-induced hepatitis $(11,37)$, was examined in the IFN- $\gamma$, STAT1, and IL-6 knockout mice. Liver lymphocyte activation was determined by FACS analysis of early activation marker $\mathrm{CD} 69^{+}$. As shown in Figures 6 , a, b, and c, administration of Con A caused a significant increase in $\mathrm{CD}^{2} 9^{+}$positive cells (lower- and upper-right quadrant in $\mathrm{CD} 4^{+} / \mathrm{CD} 69^{+}$panel) in three strains of wild-type mice and $I L-6^{-1-}$ mice, but such activation was almost completely abolished in $\mathrm{STAT1}^{-/-}$mice and $I F N-\gamma^{\prime-}$ mice. These findings 


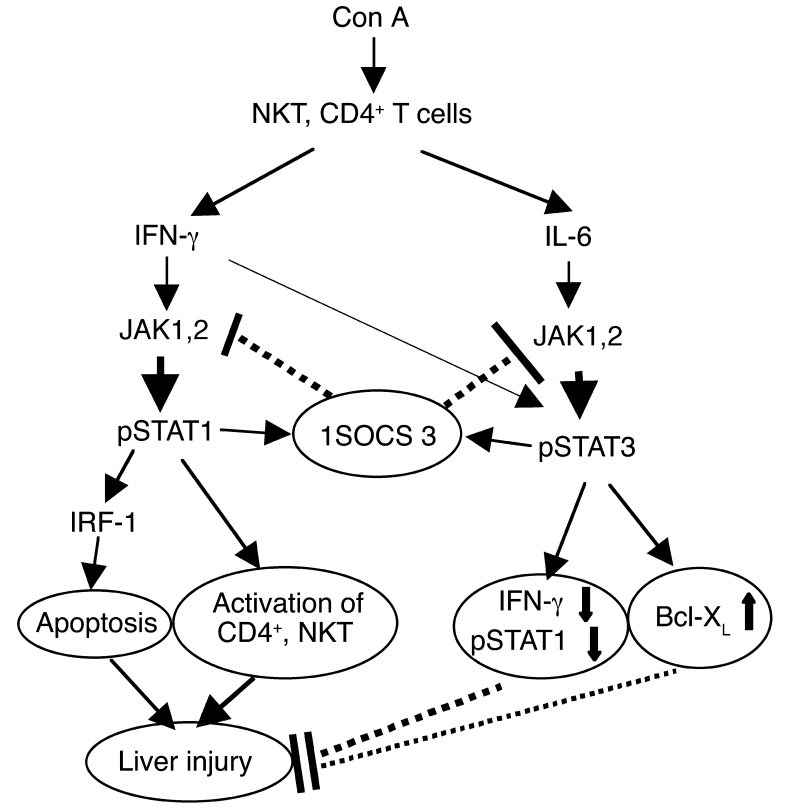

Figure 7

A model illustrating opposing roles of STAT1 and STAT3 in Con Ainduced hepatitis. Con A activates multiple immune cells, including NK T cells and $C D 4^{+} T$ cells, and induces the release of a variety of cytokines. IFN- $\gamma$ induces activation of JAK 1 and JAK 2 and consequent activation of STAT1. IFN- $\gamma /$ STAT1 play an essential role in $\mathrm{CD}^{+}$and NK T cell activation, which, in turn, directly or indirectly induce liver injury. IFN- $\gamma /$ STAT1 also induce expression of proapoptotic IRF-1 protein, which mediates liver apoptosis and injury. IL- 6 and IFN- $\gamma$ activate JAK1 and JAK2 and consequently induce STAT3 activation, followed by induction of $\mathrm{BCl}-\mathrm{X}_{\mathrm{L}}$ and other antiapoptotic factors, which protect against hepatic necrosis and apoptosis. IL-6 activation of STAT3 also downregulates IFN- $\gamma$ and IFN- $\gamma$ signaling and consequently suppresses IFN- $\gamma / \mathrm{STAT} 1$-induced liver injury. Activated STAT1 and STAT3 inhibit one another, at least in hepatocytes, by the induction of SOCS.

suggest that activation of total liver lymphocytes including $\mathrm{CD}^{+}$and $\mathrm{NK} \mathrm{T}$ cells is suppressed in $S T A T 1^{-/-}$mice and $I F N-\gamma^{-1}$ mice. Furthermore, Con A injection caused a significant increase in $\mathrm{CD} 4^{+} \mathrm{CD} 69^{+}$ double-positive cells (upper-right quadrant in $\mathrm{CD}^{+} / \mathrm{CD} 9^{+}$panel) in wild-type mice and $\mathrm{IL-} \mathrm{6}^{-/-}$mice, but not in $\mathrm{STAT1}^{-/-}$mice and $\mathrm{IFN}-\gamma^{-/-}$mice (Figure 6, $\mathrm{a}, \mathrm{b}$, and c), suggesting that activation of $\mathrm{CD}^{+}$cells is inhibited in $\mathrm{STAT1}^{-/-}$mice and $\mathrm{IFN}-\gamma^{\prime-}$ mice.

It has been shown that NK T cells are rapidly activated and consequently depleted after administration of Con A $(11,37)$, suggesting that NK T cell activation results in depletion. As shown in Figure 6, injection of Con A led to significant depletion of NK $\mathrm{T}$ cells $\left(\mathrm{NK} 1.1^{+} \mathrm{CD}^{+}\right.$double-positive cells in upperright quadrant) in wild-type mice, but not in STAT1 $1^{-/-}$and $I F N-\gamma^{-1-}$ mice. On the contrary, similar NK T cell depletion was observed in $I L-6^{-/-}$mice compared with wild-type mice (Figure 6, $\mathrm{c}$ and d). These findings suggest that NK T cell activation is impaired in $S T A T 1^{-/-}$and $I F N-\gamma^{-/}$mice, but not in $I L^{-6^{-/-}}$mice in Con A-mediated hepatitis.

\section{Discussion}

Here, data from studies using an established model of Con A-induced hepatitis suggest that $\mathrm{T}$ cell-mediated liver injury is tightly controlled by STAT1 and STAT3, which is summarized in a proposed model in Figure 7. In this model, IFN- $\gamma$ activation of STAT 1 plays a harmful role in Con A-induced liver injury by activation of $\mathrm{CD}^{+}$and NK T cells and directly inducing hepatocyte death. IL-6 activation of STAT3 protects against Con A-induced liver injury by suppression of IFN- $\gamma$ signaling and induction of Bcl- $\mathrm{X}_{\mathrm{L}}$. STAT1 and STAT3 in hepatocytes also negatively regulate one another through the induction of SOCSs.

Essential role of IFN- $\gamma$ activation of STAT1 in Con $A$-induced hepatitis. STAT1 was activated and induced after injection of Con A (Figures 1, 2, 4, and 5). IFN- $\gamma$ is the major cytokine responsible for STAT1 activation and induction because such activation was almost completely suppressed in $I F N-\gamma^{/-}$mice (Figure 4). Disruption of the IFN- $\gamma$ gene or the STAT1 gene abolished elevated ALT activities and necrosis in Con A-induced hepatitis (Figures 2 and 4), suggesting that IFN- $\gamma /$ STAT1 play an essential role in Con A-induced hepatitis. In addition to this model, IFN- $\gamma / \mathrm{STAT} 1$ have also been implicated in LPS/D-galactosamine-induced liver injury (our unpublished data) and SOCS1 deficiency-induced hepatitis $(38,39)$. Activation of $\mathrm{CD}^{+}$and NK T cells has been shown to play a critical role in Con A-mediated hepatitis $(11,37)$; however, such activation was markedly attenuated in $S T A T 1^{-/-}$or $I F N-\gamma^{-/}$mice (Figure 6), indicating that IFN- $\gamma /$ STAT1 is essential for $\mathrm{CD}^{+}$and NKT cell activation in Con A-mediated hepatitis. The mechanism underlying IFN- $\gamma /$ STAT1-mediated activation of CD4 and NK T cells is not clear. Ivashkiv et al. (40) has reported that treatment of $\mathrm{T}$ cells with phytohemagglutinin resulted in a delayed activation of STAT1, possibly through induction of IFN- $\gamma$. Therefore, it is plausible that Con A activates $\mathrm{CD}^{+}$and NK T cells by an IFN- $\gamma /$ STAT1-dependent pathway, leading to liver damage. Additionally, IFN- $\gamma /$ STAT induction of the proapoptotic protein IRF-1 in hepatocytes and subsequent induction of hepatocyte apoptosis may also contribute to liver damage in Con A-mediated hepatitis, because significant apoptosis has been reported in Con A-induced hepatitis $(13,14,41-45)$ and IFN- $\gamma$ is able to directly cause or synergistically potentiate TNF- $\alpha$-induced hepatocyte apoptosis by a IRF-1-dependent mechanism (ref. 46, our unpublished data).

Protective role of STAT3 activation in T cell-mediated hepatitis. IL-6 activation of STAT3 plays an important role in protection against liver injury induced by various toxins (25-28). Here we demonstrate that attenuated STAT3 signaling in $I L-6^{-/}$mice correlates with exacerbated liver injury (Figure 5b) and that administration of exogenous IL-6 prevents Con A-induced liver injury (Figure $5 \mathrm{e}$ ), suggesting that IL-6/STAT3 protects against liver damage in Con A-mediated hepatitis. The protective effects of IL-6/STAT3 is unlikely to be 
mediated by suppression of inflammation because similar $\mathrm{CD}^{+}$and NK T cell activation were observed in $I L-6^{-/-}$and wild-type mice in Con A-mediated hepatitis (Figure 6). Con A injection-induced elevation of serum IFN- $\gamma$ levels, STAT1 activation, and STAT1-controlled proapoptotic IRF-1 gene are enhanced in $\mathrm{IL}^{-6^{-/-}}$mice (Figure 5) but suppressed by administration of recombinant IL-6 (our unpublished data and ref. 47), suggesting that suppression of IFN- $\gamma$ production and signaling is probably one of the major mechanisms contributing to the protective effect of IL-6/STAT3 in Con A-induced hepatitis. Additionally, induction of the antiapoptotic $\mathrm{Bcl}-\mathrm{X}_{\mathrm{L}}$ protein expression in hepatocytes may be another mechanism contributing to IL-6/STAT3-mediated protection against Con Ainduced liver injury because $\mathrm{Bcl}-\mathrm{X}_{\mathrm{L}}$, which is elevated and positively regulated by IL-6/STAT3 in Con Ainduced hepatitis (Figure 2d and Figure 5a), has been implicated in protection against hepatocyte death induced by a variety of hepatoxins, including CCl4 (26), Fas ligand (27, 48), alcohol (28), and TNF- $\alpha$ (48).

IL-6 is the major cytokine responsible for STAT3 activation in liver regeneration (25) and CCl4-induced liver injury (26), since such activation is not detectable in $I L^{-6^{-/-}}$mice under these conditions. However, STAT3 activation in Con A-induced hepatitis was reduced only about $50 \%$ in $\mathrm{IL}^{-6^{-/}}$mice (Figure 5), suggesting that other cytokines are also involved in STAT3 activation in this model. Three lines of evidence suggest that IFN- $\gamma$ partially contributes to STAT3 activation in Con A-induced hepatitis. First, IFN- $\gamma$ activated STAT3 in primary mouse hepatocytes in vitro (Figure 3 ) and in primary human hepatocytes (31). Second, injection of IFN- $\gamma$ induced significant activation of STAT3 in the liver (data not shown). Finally, elimination of STAT1 activation in $\mathrm{STAT1}^{-/-}$mice markedly enhanced STAT3 activation after injection of Con A, while disruption of STAT1 activation in $I F N-\gamma^{/-}$mice only slightly enhanced STAT3 activation. This is probably because IFN- $\gamma$-mediated activation of STAT3 signal is also disrupted in $I F N-\gamma^{-/}$mice.

SOCS-mediated inhibitory cross-talk between STAT1 and STAT3 in hepatocytes in Con A-induced hepatitis. In the present paper, we clearly demonstrate that activation of STAT1 promotes, whereas activation of STAT3 protects against, Con A-induced liver injury. In addition to such functional antagonism, STAT1 and STAT3 also mutually inhibit one another, at least in hepatocytes, by the induction of SOCS. To date, eight SOCS proteins (SOCS1-SOCS7 and CIS) have been identified (20-22). Among them, SOCS1 and SOCS3 appear to be the most potent inhibitors of cytokine signaling (49). Here, we demonstrate that both SOCS1 and SOCS3 are markedly induced, whereas SOCS2 and CIS are only slightly enhanced in the liver of Con A-induced hepatitis, suggesting that SOCS1 and SOCS3 may be the most important suppressors of STAT1 and STAT3 signaling in this model. Several lines of evidence indicate that induction of SOCS1 in the liver is mainly controlled by STAT1 activation. First, disruption of the STAT1 gene in $S T A T 1^{-/-}$mice almost completely abolished Con A-mediated induction of SOCS1, although STAT3 activation was markedly enhanced and prolonged in these mice (Figure 2). Second, IFN- $\gamma$-mediated induction of SOCS1 was completely abolished in primary $\mathrm{STAT1}^{-/-}$mouse hepatocytes, whereas induction of SOCS3 was enhanced in these cells. Third, enhanced STAT1 activation correlated with prolonged induction of SOCS1 mRNA expression in $I L^{-6^{-/}}$mice (Figure 5). Finally, STAT1 plays an essential role in induction of IRF-1 (Figures 2, 3, and 4), a key transcription factor controlling SOCS1 gene transcription (50). SOCS1 was originally identified in a functional screen for factors that inhibit IL-6 signaling (51) and later identified as a general negative feedback inhibitor for cytokine signaling $(21,22)$. Thus, STAT1-mediated induction of SOCS1 not only is a negative feedback loop for STAT1 activation, but also attenuates activation of STAT3 in Con A-induced hepatitis.

SOCS3 was induced in Con A-mediated hepatitis, and such induction positively correlated with STAT3 activation (Figure 2d and Figure 5a). Elimination of the STAT1 gene did not reduce, but rather enhanced, SOCS3 induction (Figure $2 \mathrm{~d}$ and Figure 3). Collectively, these findings suggest that STAT3 plays a more important role than STAT1 in inducing SOCS3 in this model of hepatitis. Induction of SOCS3 controlled predominantly by STAT3 in the liver is also suggested in another model of liver regeneration (52). In this model, SOCS3 but not SOCS1 is markedly induced, which correlates with activation of STAT3 but absent STAT1 activation (52). SOCS3 has been shown to negatively regulate STAT1 and STAT3 activation by inhibition of JAKs $(21,22)$. Thus, it is very likely that induction of SOCS3 attenuates both STAT1 and STAT3 in Con A-induced hepatitis.

In summary, our findings suggest that $\mathrm{T}$ cell-induced hepatitis is tightly controlled by mutual functional antagonism of IFN- $\gamma /$ STAT1 and IL-6/STAT3, which negatively regulate one another through the induction of SOCS. Elevation of IFN- $\gamma$ and IL- 6 is observed not only in this Con A-induced murine model of hepatitis, but also in a variety of human liver disorders, including viral hepatitis $(7,53-56)$, autoimmune hepatitis $(6,56$, 57), primary biliary cirrhosis (58), and alcoholic liver disease (59), suggesting that human liver disorders may also be controlled by mutual antagonism of IFN- $\gamma /$ STAT1 and IL-6/STAT3. Modulation of such mutual antagonism between STAT1 and STAT3 could offer a novel approach in the treatment of $\mathrm{T}$ cell-mediated liver damage in human liver disease.

\footnotetext{
1. Kita, H., Mackay, I.R., Van De Water, J., and Gershwin, M.E. 2001. The lymphoid liver: considerations on pathways to autoimmune injury. Gastroenterology. 120:1485-1501.

2. Heneghan, M.A., and McFarlane, I.G. 2002. Current and novel immunosuppressive therapy for autoimmune hepatitis. Hepatology. 35:7-13.

3. Bogdanos, D.P., Mieli-Vergani, G., and Vergani, D. 2000. Virus, liver and autoimmunity. Dig. Liver Dis. 32:440-446.

4. Rehermann, B., and Chisari, F.V. 2000. Cell-mediated immune response to the hepatitis C virus. Curr. Top. Microbiol. Immunol. 242:299-325.

5. Chedid, A., et al. 1993. Cell-mediated hepatic injury in alcoholic liver
} 
disease. Veterans Affairs Cooperative Study Group 275. Gastroenterology. 105:254-266.

6. Lohr, H.F., et al. 1996. Autoreactive CD4+ LKM-specific and anticlonotypic T-cell responses in LKM-1 antibody-positive autoimmune hepatitis. Hepatology. 24:1416-1421.

7. Napoli, J., Bishop, G.A., McGuinness, P.H., Painter, D.M., and McCaughan, G.W. 1996. Progressive liver injury in chronic hepatitis C infection correlates with increased intrahepatic expression of Th1-associated cytokines. Hepatology. 24:759-765.

8. Rosen, H.R., et al. 2002. Frequencies of HCV-specific effector CD4+ T cells by flow cytometry: correlation with clinical disease stages. Hepatology. 35:190-198.

9. Chang, K.M., et al. 2001. Differential CD4(+) and CD8(+) T-cell responsiveness in hepatitis C virus infection. Hepatology. 33:267-276.

10. Chisari, F.V. 1997. Cytotoxic T cells and viral hepatitis. J. Clin. Invest. 99:1472-1477.

11. Tiegs, G., Hentschel, J., and Wendel, A. 1992. A T cell-dependent experimental liver injury in mice inducible by concanavalin A. J. Clin. Invest. 90:196-203.

12. Kaneko, Y., et al. 2000. Augmentation of Valpha14 NKT cell-mediated cytotoxicity by interleukin 4 in an autocrine mechanism resulting in the development of concanavalin A-induced hepatitis. J. Exp. Med. 191:105-114.

13. Fiorucci, S., et al. 2000. NO-aspirin protects from $\mathrm{T}$ cell-mediated liver injury by inhibiting caspase-dependent processing of Th1-like cytokines. Gastroenterology. 118:404-421.

14. Tagawa, Y., Sekikawa, K., and Iwakura, Y. 1997. Suppression of concanavalin A-induced hepatitis in IFN-gamma(-/-) mice, but not in TNFalpha(-/-) mice: role for IFN-gamma in activating apoptosis of hepatocytes. J. Immunol. 159:1418-1428.

15. Wolf, D., et al. 2001. TNF-alpha-induced expression of adhesion molecules in the liver is under the control of TNFR1-relevance for concanavalin A-induced hepatitis. J. Immunol. 166:1300-1307.

16. Schindler, C. 1999. Cytokines and JAK-STAT signaling. Exp. Cell Res. 253:7-14.

17. Darnell, J.E., Jr., Kerr, I.M., and Stark, G.R. 1994. Jak-STAT pathways and transcriptional activation in response to IFNs and other extracellular signaling proteins. Science. 264:1415-1421.

18. Ihle, J.N. 1996. STATs: signal transducers and activators of transcription. Cell. 84:331-334.

19. Leonard, W.J. 2001. Role of Jak kinases and STATs in cytokine signal transduction. Int. J. Hematol. 73:271-277.

20. Chen, X.P., Losman, J.A., and Rothman, P. 2000. SOCS proteins, regulators of intracellular signaling. Immunity. 13:287-290.

21. Nicola, N.A., et al. 1999. Negative regulation of cytokine signaling by the SOCS proteins. Cold Spring Harb. Symp. Quant. Biol. 64:397-404.

22. Naka, T., Fujimoto, M., and Kishimoto, T. 1999. Negative regulation of cytokine signaling: STAT-induced STAT inhibitor. Trends Biochem. Sci. 24:394-398.

23. Kamiya, A., et al. 1999. Fetal liver development requires a paracrine action of oncostatin $\mathrm{M}$ through the gp130 signal transducer. EMBOJ. 18:2127-2136

24. Baumann, H., and Gauldie, J. 1994. The acute phase response. Immunol. Today 15:74-80.

25. Cressman, D.E., et al. 1996. Liver failure and defective hepatocyte regeneration in interleukin-6- deficient mice. Science. 274:1379-1383.

26. Kovalovich, K., et al. 2000. Increased toxin-induced liver injury and fibrosis in interleukin-6-deficient mice. Hepatology. 31:149-159.

27. Kovalovich, K., et al. 2001. Interleukin- 6 protects against Fas-mediated death by establishing a critical level of anti-apoptotic hepatic proteins FLIP, Bcl-2, and Bcl-xL. J. Biol. Chem. 276:26605-26613.

28. Hong, F., et al. 2002. Elevated interleukin-6 during ethanol consumption acts as a potential endogenous protective cytokine against ethanolinduced apoptosis in the liver: involvement of induction of $\mathrm{Bcl}-2$ and $\mathrm{Bcl}-\mathrm{x}(\mathrm{L})$ proteins. Oncogene. 21:32-43.

29. Meraz, M.A., et al. 1996. Targeted disruption of the Stat 1 gene in mice reveals unexpected physiologic specificity in the JAK-STAT signaling pathway. Cell. 84:431-442.

30. Durbin, J.E., Hackenmiller, R., Simon, M.C., and Levy, D.E. 1996. Targeted disruption of the mouse Stat 1 gene results in compromised innate immunity to viral disease. Cell. 84:443-450.

31. Radaeva, S., et al. 2002. Interferon-alpha activates multiple STAT signals and down-regulates c-Met in primary human hepatocytes. Gastroenterology. 122:1020-1034.

32. Huang, Y.Q., Li, J.J., and Karpatkin, S. 2000. Thrombin inhibits tumor cell growth in association with up-regulation of $\mathrm{p} 21$ (waf/cip1) and caspases via a p53-independent, STAT-1-dependent pathway. J. Biol. Chem. 275:6462-6468.

33. Grad, J.M., Zeng, X.R., and Boise, L.H. 2000. Regulation of Bcl-xL: a little bit of this and a little bit of STAT. Curr. Opin. Oncol. 12:543-549.

34. Han, Z., Hendrickson, E.A., Bremner, T.A., and Wyche, J.H. 1997. A sequential two-step mechanism for the production of the mature p17:p12 form of caspase-3 in vitro. J. Biol. Chem. 272:13432-13436.

35. Kusters, S., Gantner, F., Kunstle, G., and Tiegs, G. 1996. Interferon gamma plays a critical role in $\mathrm{T}$ cell-dependent liver injury in mice initiated by concanavalin A. Gastroenterology. 111:462-471.

36. Mizuhara, H., et al. 1994. T cell activation-associated hepatic injury: mediation by tumor necrosis factors and protection by interleukin 6 . J. Exp. Med. 179:1529-1537.

37. Takeda, K., et al. 2000. Critical contribution of liver natural killer T cells to a murine model of hepatitis. Proc. Natl. Acad. Sci. USA. 97:5498-5503.

38. Alexander, W.S., et al. 1999. SOCS1 is a critical inhibitor of interferon gamma signaling and prevents the potentially fatal neonatal actions of this cytokine. Cell. 98:597-608

39. Naka, T., et al. 2001. SOCS-1/SSI-1-deficient NKT cells participate in severe hepatitis through dysregulated cross-talk inhibition of IFNgamma and IL-4 signaling in vivo. Immunity. 14:535-545.

40. Ivashkiv, L.B., Schmitt, E.M., and Castro, A. 1996. Inhibition of transcription factor Stat 1 activity in mononuclear cell cultures and T cells by the cyclic AMP signaling pathway. J. Immunol. 157:1415-1421.

41. Kunstle, G., et al. 1999. Concanavalin A hepatotoxicity in mice: tumor necrosis factor-mediated organ failure independent of caspase-3-like protease activation. Hepatology. 30:1241-1251.

42. Chen, D., et al. 2001. CD44-deficient mice exhibit enhanced hepatitis after concanavalin A injection: evidence for involvement of CD44 in activation-induced cell death. J. Immunol. 166:5889-5897.

43. Kim, K.M., et al. 2000. A broad-spectrum caspase inhibitor blocks concanavalin A-induced hepatitis in mice. Clin. Immunol. 97:221-233.

44. Ksontini, R., et al. 1998. Disparate roles for TNF-alpha and Fas ligand in concanavalin A-induced hepatitis. J. Immunol. 160:4082-4089.

45. Tagawa, Y., Kakuta, S., and Iwakura, Y. 1998. Involvement of Fas/Fas ligand system-mediated apoptosis in the development of concanavalin Ainduced hepatitis. Eur. J. Immunol. 28:4105-4113.

46. Kano, A., Haruyama, T., Akaike, T., and Watanabe, Y. 1999. IRF-1 is an essential mediator in IFN-gamma-induced cell cycle arrest and apoptosis of primary cultured hepatocytes. Biochem. Biophys. Res. Commun. 257:672-677.

47. Mizuhara, H., et al. 1996. Critical involvement of interferon gamma in the pathogenesis of T-cell activation-associated hepatitis and regulatory mechanisms of interleukin- 6 for the manifestations of hepatitis. Hepatology. 23:1608-1615.

48. de la Coste, A., et al. 1999. Differential protective effects of Bcl-xL and Bcl-2 on apoptotic liver injury in transgenic mice. Am. J. Physiol. 277:G702-G708.

49. Nicholson, S.E., et al. 1999. Mutational analyses of the SOCS proteins suggest a dual domain requirement but distinct mechanisms for inhibition of LIF and IL-6 signal transduction. EMBOJ. 18:375-385.

50. Saito, H., et al. 2000. IFN regulatory factor-1-mediated transcriptional activation of mouse STAT-induced STAT inhibitor- 1 gene promoter by IFN-gamma. J. Immunol. 164:5833-5843.

51. Starr, R., et al. 1997. A family of cytokine-inducible inhibitors of signaling. Nature. 387:917-921.

52. Campbell, J.S., et al. 2001. Expression of suppressors of cytokine signaling during liver regeneration. J. Clin. Invest. 107:1285-1292.

53. Koziel, M.J. 1999. Cytokines in viral hepatitis. Semin. Liver Dis. 19:157-169.

54. Sobue, S., et al. 2001. Th1/Th2 cytokine profiles and their relationship to clinical features in patients with chronic hepatitis $\mathrm{C}$ virus infection. J. Gastroenterol. 36:544-551.

55. Cui, W., Dong, Y., Fang, F., and Li, G. 1998. Tumor necrosis factor alpha, interleukin-6, interleukin-8, and interferon alpha in children with viral hepatitis. J. Tongji Med. Univ. 18:247-249.

56. al-Wabel, A., al-Janadi, M., and Raziuddin, S. 1993. Cytokine profile of viral and autoimmune chronic active hepatitis. J. Allergy Clin. Immunol. 92:902-908.

57. Maggiore, G., De Benedetti, F., Massa, M., Pignatti, P., and Martini, A. 1995. Circulating levels of interleukin-6, interleukin-8, and tumor necrosis factor-alpha in children with autoimmune hepatitis. J. Pediatr. Gastroenterol. Nutr. 20:23-27.

58. Martinez, O.M., Villanueva, J.C., Gershwin, M.E., and Krams, S.M. 1995 Cytokine patterns and cytotoxic mediators in primary biliary cirrhosis. Hepatology. 21:113-119.

59. McClain, C.J., Barve, S., Deaciuc, I., Kugelmas, M., and Hill, D. 1999. Cytokines in alcoholic liver disease. Semin. Liver Dis. 19:205-219. 